Research Article

\title{
Carbon Nanotube Effect on the Ductility, Flexural Strength, and Permeability of Concrete
}

\author{
Mohamed O. Mohsen $\mathbb{D}^{1},{ }^{1}$ Mohamed S. Al Ansari, ${ }^{1}$ Ramzi Taha, ${ }^{2}$ Nasser Al Nuaimi $\mathbb{D}^{1}{ }^{1}$ \\ and Ala Abu Taqa $\mathbb{D}^{1}$ \\ ${ }^{1}$ Department of Civil and Architectural Engineering, Qatar University, P.O. Box 2713, Doha, Qatar \\ ${ }^{2}$ College of Engineering, Phoenicia University, P.O. Box 11-7790, Beirut, Lebanon
}

Correspondence should be addressed to Mohamed O. Mohsen; 200202128@qu.edu.qa

Received 1 April 2019; Revised 8 August 2019; Accepted 20 August 2019; Published 7 October 2019

Academic Editor: Andrew R. Barron

Copyright (C) 2019 Mohamed O. Mohsen et al. This is an open access article distributed under the Creative Commons Attribution License, which permits unrestricted use, distribution, and reproduction in any medium, provided the original work is properly cited. The publication of this article was funded by Qatar National Library.

\begin{abstract}
Recently, remarkable types of carbon nanofilaments called carbon nanotubes (CNTs) have raised the interest of many concrete and cementitious composite researchers due to their significant mechanical, electrical, thermal, kinetic, and chemical properties. These nanofilaments are considered promising applicants to use in producing high-performance cement-based composite materials. In this research, the effect of CNT use on the flexural strength, strain capacity, permeability, and microstructure of concrete was investigated. Concrete batches of $0,0.03,0.08,0.15$, and $0.25 \mathrm{wt}$.\% CNTs were prepared using a mixing method that consisted of a 30 -minute solution sonication and a 60 -minute batch mixing. On the $28^{\text {th }}$ day, the mechanical properties were determined. The results indicated that concrete prepared using high CNT contents of 0.15 and $0.25 \mathrm{wt} . \%$ increased the flexural strength by more than $100 \%$ in comparison with $0 \%$ CNT concrete. Furthermore, the results showed that CNTs would increase the ductility of concrete beams by about $150 \%$. The permeability test results showed the benefits of CNT inclusion in reducing the permeability of concrete. The permeability coefficient $(\mathrm{kT})$ decreased by at least $45 \%$ when CNTs were added to concrete. A qualitative microstructural analysis illustrated the uniform dispersion of CNT filaments within the concrete hydration products in all batches.
\end{abstract}

\section{Introduction}

Concrete is the most well-known material used in building construction. It comprises of water, aggregates, and cement. These ingredients are usually combined with steel reinforcement to achieve the desired mechanical properties. However, a major shortcoming in concrete is related to its brittle nature caused by its cement constituent, which is characterized by its poor resistance to crack formation, low tensile strength, and low strain capacities. In the past decade, researchers [1-9] started testing unique types of carbon fibers with nanosized diameters and micron-sized lengths, called carbon nanotubes (CNTs) and carbon nanofibers (CNFs). Those types of fibers have extraordinary mechanical, electrical, thermal, kinetic, and chemical properties, making them promising applicants in producing highperformance cement-based composite materials. However, findings reported in the literature were contradictory. Some results confirmed the benefits of the tested composites' mechanical properties [10-15], while others showed no improvement, and in some other cases, there was a reduction in the mechanical properties [16-19]. The main reason for these differences in the obtained results is attributed to the nanofilaments' weak dispersion in water and cement. Few researchers $[20,21]$ were successful in obtaining an acceptable dispersion quality in water; however, when they blended their solutions with cement, poor dispersions and agglomerations were observed. Recently, Mohsen et al. [22] succeeded in improving the dispersion of CNTs in cement paste by performing an innovative mixing procedure. The authors tested the effect of different mixing durations of $1.5,15,30$, and 60 minutes on the flexural strength of cement and CNT composites. It was shown that increasing the mixing duration of the paste that contained CNTs would 
result in better dispersion of the constituents and in having lower void percent at the microstructural scale. This improvement resulted in a flexural strength increase of about $100 \%$ compared to a plain cement paste. Also, the researchers conducted a set of experiments that investigated the effect of several parameters on the dispersion of CNTs in cement paste, such as CNT weight fractions, diameters, and lengths $[23,24]$.

Most studies performed in this field investigated the effect of CNTs or CNFs usage on cement paste properties. At this stage, the reasons for investigating the effect of such materials on cement paste only is the simplicity of capturing or tracking the nanofilaments' dispersion within the matrix compared to mortars and concrete, and the large costs of preparing concrete using the nanofilaments. Few studies investigated the effect of adding carbon nanofilament on the properties of mortar [15, 25-27]. Several mixing procedures and mix proportions were proposed. However, the challenges known with the cement paste studies such as dispersion quality, strength discrepancies, and optimum mix proportions were still observed. The effect of CNT addition on the properties of concrete was recently investigated. Few studies focused on studying the effect of CNTs on the mechanical and physical properties of lightweight foam concrete prepared using small-scale samples, while others investigated the effect of CNTs on the properties of ordinary concrete. Krämer et al. [28] studied the effect of using CNTto-cement weight fractions of 0.05 and $0.075 \%$ with samples of foamed concrete. On the $28^{\text {th }}$ day, their results showed an improvement in the flexural and compressive strengths of about 40 and $7.5 \%$, respectively. In another study, Krämer et al. [29] combined ultra-high-performance concrete (UHPC) and three-phase-foams to create mixes that included both carbon nanotubes (CNTs) and titanium oxide nanoparticles $\left(\mathrm{TiO}_{2}\right)$. Their results demonstrated a strength improvement compared with the control batches. Luo et al. [30] investigated the effect of using CNT-to-cement weight fractions of 0.05 to $0.1 \%$ on several properties of foam concrete. They showed the ability of CNTs to decrease the average pore diameter and to increase the compressive strength by about $30 \%$ in comparison with the control batch. Similarly, Wang et al. [31] investigated the effect of MWCNTs on the compressive strength, chloride penetration, and freeze-thaw resistance of ordinary concrete cylinders comprising different water-to-cement ratios. Their results showed an improvement of $108 \%$ in the compressive strength of concrete having sodium polyacrylate-treated CNTs. Qissab and Abbas [32] investigated the behavior of reinforced concrete beams with short and long MWCNTs under monotonic loading. CNTto-cement weight fractions of $0.03,0.045$, and $0.06 \%$ were used. Their results showed an improvement in the compressive, splitting tensile and flexural strength of all batches compared to the control mix. The batch containing $0.045 \%$ long CNTs achieved the highest mechanical properties among all other batches. Hawreen et al. [33] analyzed the durability of concrete reinforced by different types and weight fractions of CNTs. The results showed that a compressive strength improvement of about $20 \%$ could be achieved using a CNTto-cement weight fraction of $0.1 \%$.
Up to date, the results obtained from studies that investigated the effect of long CNT weight fractions higher than $0.2 \%$ on ordinary concrete mechanical, physical, and microstructural properties were not positive. The proposed research will combine CNT reinforcement in concrete using a prolonged mixing technique to investigate their effect on the concrete mechanical and physical properties.

\section{Testing Methodology}

2.1. Testing Matrix. In this research, concrete batches containing CNTs of weight fractions ranging between 0.03 and 0.25 wt. $\%$ were prepared. Table 1 presents the experimental design matrix of the batches' compositions. The testing methodology started with the preparation of the batches and the casting of the specimens $(100 \times 100 \times 500 \mathrm{~mm})$, followed by measurements of their flexural strength, deflection, and permeability. Their microstructures were then analyzed using a scanning electron microscope (SEM).

2.2. Materials and Equipment. The cement used in this research was a Portland cement, CEM I, Class $42.5 \mathrm{R}$, complying with EN 197-1. It was bought from Qatar National Cement Company (QNCC). The mixing water used was tap water attached to a filter. The point-of-use filter fixed on a faucet helps in removing chlorine, lead, and bacterial contaminants. The fine and coarse aggregates used in preparing the concrete samples were bought from Qatar Primary Materials Company (QPMC). The properties of the materials met the requirements of ASTM C-33, Standard Specification for Concrete Aggregates. The fine aggregates consisted of natural sand, while the coarse aggregates consisted of gabbro stones. The used CNTs were multiwalled carbon nanotubes (MWCNTs) produced using the catalytic chemical vapor deposition (CVD) process and provided by US Research Nanomaterials. The physical properties of the nanofilaments are shown in Table 2. Commercial polycarboxylate waterreducing admixture, named ADVA Cast 575, provided by GRACE Products was used as a surfactant to help improve the dispersion of the nanofilaments within the aqueous solution. The equipment used in the experiments included an ultrasonic wave mixer, VCX 750 Model connected to a probe to measure the solution temperature, supplied by Sonics and Materials Inc.; an 85-liter site concrete mixer supplied by Humboldt; a strength testing machine attached to a highprecision linear variable differential transformer (LVDT) device of $2 \mathrm{~mm}$ travel provided by Controls Inc.; a concrete vibrator; $100 \times 100 \times 500 \mathrm{~mm}$ steel molds; a permeability tester supplied by Proceq SA; and a scanning electron microscope (SEM), Nova NanoSEM Model, supplied by FEI.

2.3. Mixing Procedure. The mixing procedure was divided into two parts. The first part comprised of CNT dispersion in water, while the second part comprised of mixing the dispersed solution with cement, coarse, and fine aggregate in the concrete mixer. The dispersion was done in nine repetitions consisting of 1.1 liters each. The reasons for performing the sonication in repetitions were related to the capacity of the sonicator available and to ensure having similar sonication 
TABLE 1: Composite concrete test batches.

\begin{tabular}{|c|c|c|c|c|c|c|c|c|c|c|}
\hline $\begin{array}{l}\text { Batch } \\
\#\end{array}$ & $\begin{array}{l}\text { Batch } \\
\text { name }\end{array}$ & $\begin{array}{l}\text { Cement } \\
(\mathrm{kg})\end{array}$ & $\begin{array}{l}\text { Water } \\
(\mathrm{kg})\end{array}$ & $\begin{array}{l}\text { Fine } \\
\text { agg. } \\
\text { (kg) }\end{array}$ & $\begin{array}{l}\text { Coarse } \\
\text { agg. } \\
\text { (kg) }\end{array}$ & $\begin{array}{l}\text { CNTs } \\
(\mathrm{g})\end{array}$ & $\begin{array}{c}\text { CNTs/cement } \\
(\%)\end{array}$ & $\begin{array}{c}\text { Total } \\
\text { superplasticizer } \\
\text { (g) }\end{array}$ & $\begin{array}{l}\text { Superplasticizer } \\
\text { used in the } \\
\text { sonication } \\
\text { process (g) }\end{array}$ & $\begin{array}{c}\text { Remaining } \\
\text { superplasticizer used in } \\
\text { CNT solution and } \\
\text { concrete mixing process } \\
(\mathrm{g})\end{array}$ \\
\hline 1 & 0 & 19.2 & 9.6 & 44 & 48 & 0 & 0 & 240 & 0 & 240 \\
\hline 2 & $0.03 \mathrm{CNT}$ & 19.2 & 9.6 & 44 & 48 & 5.8 & 0.03 & 240 & 23 & 217 \\
\hline 3 & $0.08 \mathrm{CNT}$ & 19.2 & 9.6 & 44 & 48 & 154 & 0.08 & 240 & 61.4 & 178.6 \\
\hline 4 & $0.15 \mathrm{CNT}$ & 19.2 & 9.6 & 44 & 48 & 28.8 & 0.15 & 240 & 115.2 & 124.8 \\
\hline 5 & $0.25 \mathrm{CNT}$ & 19.2 & 9.6 & 44 & 48 & 48 & 0.25 & 240 & 192 & 48 \\
\hline
\end{tabular}

TABLE 2: CNT physical properties (https://www.us-nano.com).

\begin{tabular}{|c|c|c|c|c|c|c|c|c|c|c|}
\hline $\begin{array}{l}\text { CNT } \\
\text { type }\end{array}$ & $\begin{array}{l}\text { Aspect } \\
\text { ratio }\end{array}$ & $\begin{array}{l}\text { Purity } \\
\text { (wt.\%) }\end{array}$ & $\begin{array}{c}\text { Outside } \\
\text { diameter }(\mathrm{nm})\end{array}$ & $\begin{array}{c}\text { Inside } \\
\text { diameter }(\mathrm{nm})\end{array}$ & $\begin{array}{l}\text { Length } \\
(\mu \mathrm{m})\end{array}$ & $\begin{array}{l}\text { SSA } \\
\left(\mathrm{m}^{2} / \mathrm{g}\right)\end{array}$ & Color & $\begin{array}{c}\text { Youngs } \\
\text { modulus }(\mathrm{GPa})\end{array}$ & $\begin{array}{c}\text { Tensile } \\
\text { strength }(\mathrm{GPa})\end{array}$ & $\begin{array}{l}\text { Density } \\
\left(\mathrm{g} / \mathrm{cm}^{3}\right)\end{array}$ \\
\hline $\begin{array}{l}\text { Long- } \\
\text { thin }\end{array}$ & 1,333 & $>95$ & $10-20$ & $5-10$ & $10-30$ & $>200$ & Black & 1200 & 150 & 2.6 \\
\hline
\end{tabular}

parameters such as energy, temperature, and amplitude in similar studies performed using smaller-scale mortar and cement paste samples. The surfactant/superplasticizer concentration used in the dispersion process was fixed at $4: 1$ of the selected CNT weight fraction. This amount was subtracted from the overall batch surfactant/superplasticizer amount that was constant in all batches. The nanofilaments were mixed with water and surfactant in the first mixing phase at the specified percentages (Table 1). Sonication of CNTs was done using an ultrasonic wave mixer for 30 minutes at an amplitude of $20 \%$ delivering a total applied energy of about $70 \mathrm{~kJ}$. During sonication, the temperature of the solution was kept less than $45^{\circ} \mathrm{C}$ by setting the sonicator to stop whenever the temperature of the solution exceeds $45^{\circ} \mathrm{C}$. It is worthwhile mentioning that the CNT weight fraction used at the start of the sonication process should not be considered the effective weight fraction in the composite matrix as the original amount might have some impurities and bundles that remain after the sonication process. After completing the sonication of all solutions, they were combined in two large beakers of a 5-liter capacity (Figure 1(a)). After that, the concrete mixing phase started. The mixing duration was selected to be a total of 60 minutes to provide better CNT dispersion in the concrete matrix. This was based on the previous findings of the authors where it was observed that a long mixing duration of 60 minutes could improve the CNT dispersion within the cement paste matrix and reduce the voids percent in the overall composite beams, which in return resulted in an incremental increase of about $100 \%$ in the flexural strength compared to the control plain cement batch [22]. The mixing procedure started by first placing the coarse aggregate in the mixer. Then, the CNT/water solution was added to the coarse aggregates while the mixer was on. Mixing was continued for about 5 minutes. After that, fine aggregates were added followed by cement. After adding the sand and cement, which was completed in 10 minutes, the mixing then continued for 45 minutes (Figure 1(b)). The mixture was then placed in the molds and compacted using a concrete vibrator (Figure 2(a)). Finally, the specimens were cured in a water tank for 28 days in preparation for testing (Figure 2(b)).

2.4. Flexural Strength and Load-Deflection Measurements. The flexural strength testing of concrete CNT samples was conducted according to ASTM C78/C78M-16, which is the standard test method for flexural strength of concrete using a simple beam with a third-point loading [34]. Depending on the fracture's location, the flexural strength was calculated using the following equations:

(1) If the fracture initiates in the tension surface within the middle third of the span length, the flexural strength was calculated follows:

$$
R=\frac{P L}{b d^{2}}
$$

where $R$ is the flexural strength (MPa), $P$ is the maximum applied load indicated by the testing machine $(\mathrm{N}), L$ is the span length $(\mathrm{mm}), b$ is the average width of the specimen at fracture $(\mathrm{mm})$, and $d$ is the average depth of specimen at fracture $(\mathrm{mm})$.

(2) If the fracture occurs in the tension surface outside of the middle third of the span length by less than $5 \%$ of the span length, the flexural strength was calculated as follows:

$$
R=\frac{3 P a}{b d^{2}}
$$

where $a$ is the average distance between the line of 


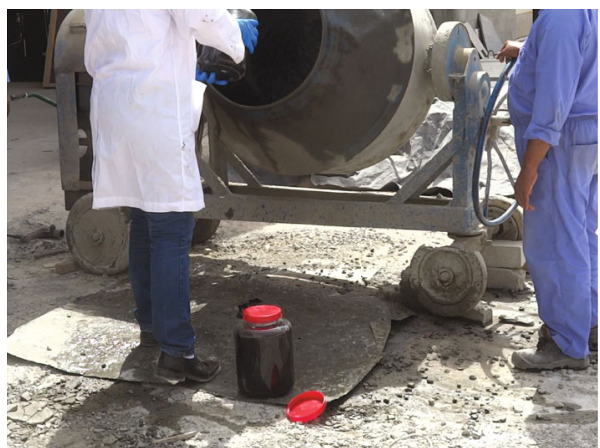

(a)

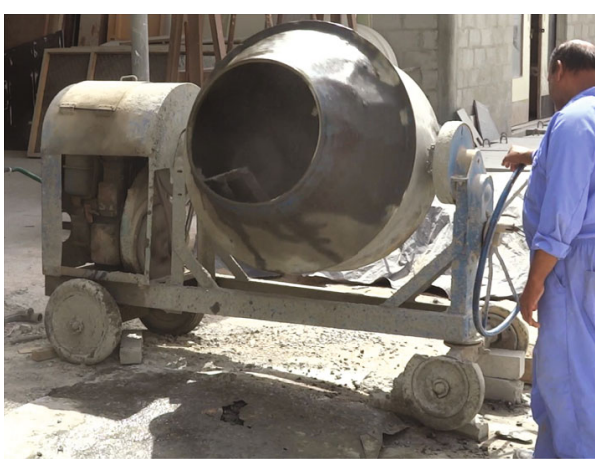

(b)

Figure 1: (a) Combined CNT solution. (b) Concrete CNT mixing.

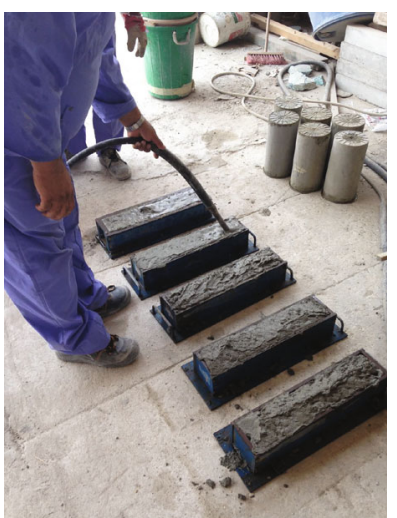

(a)

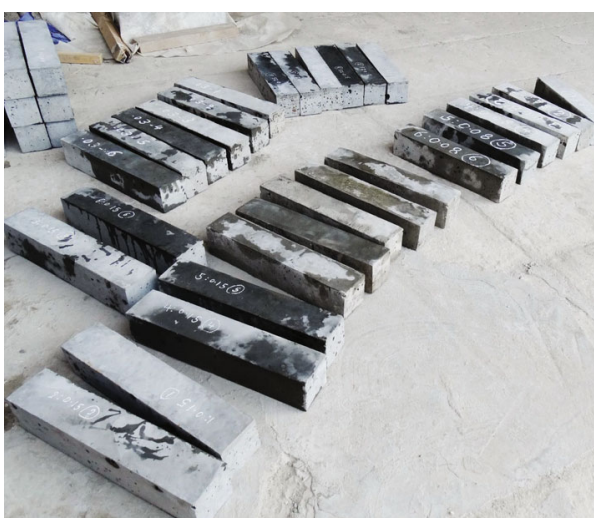

(b)

Figure 2: (a) Specimen compaction using a vibrator. (b) Specimen after 28 days of curing.

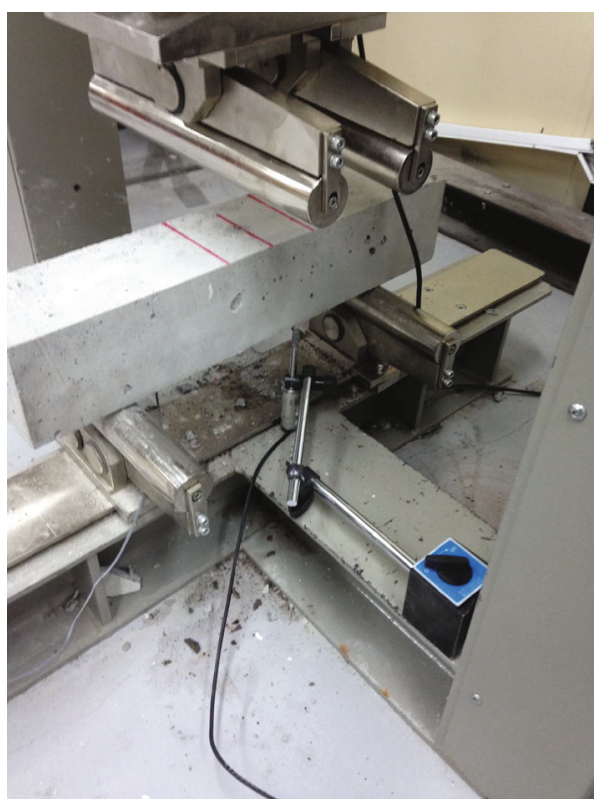

(a)

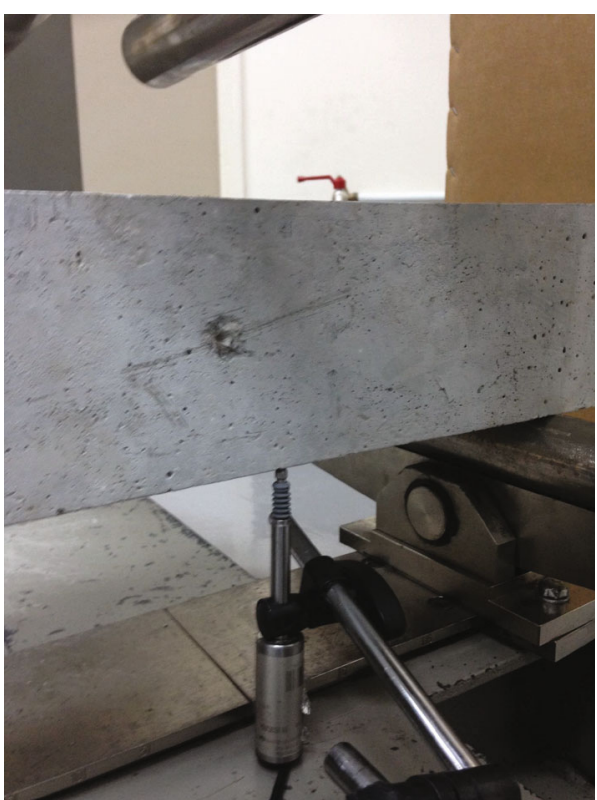

(b)

Figure 3: (a) LVDT fixing using a magnetic holder. (b) LVDT vertical alignment at midspan. 


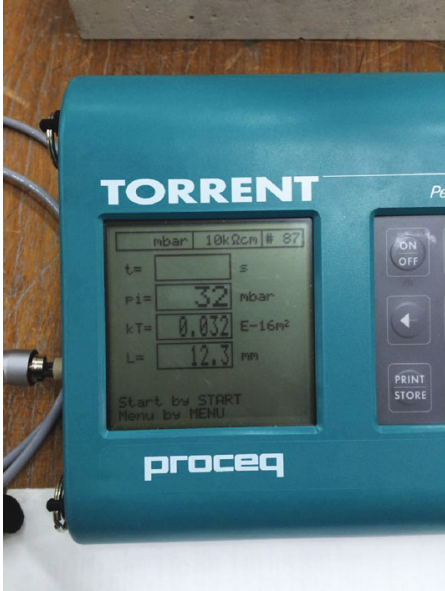

(a)

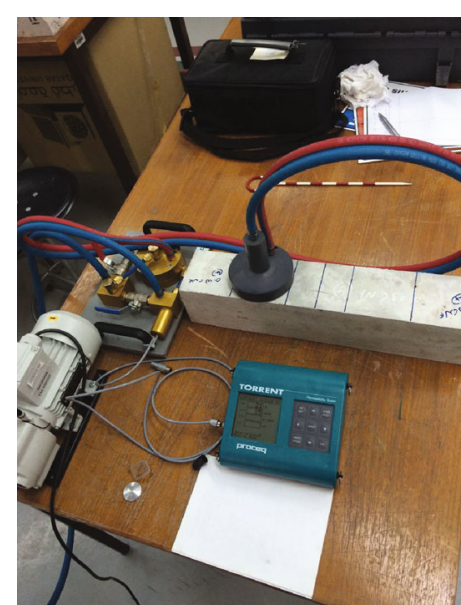

(b)

FIgURE 4: (a) Setting the permeability tester. (b) Measurements of the permeability coefficient on the concrete sample surface.

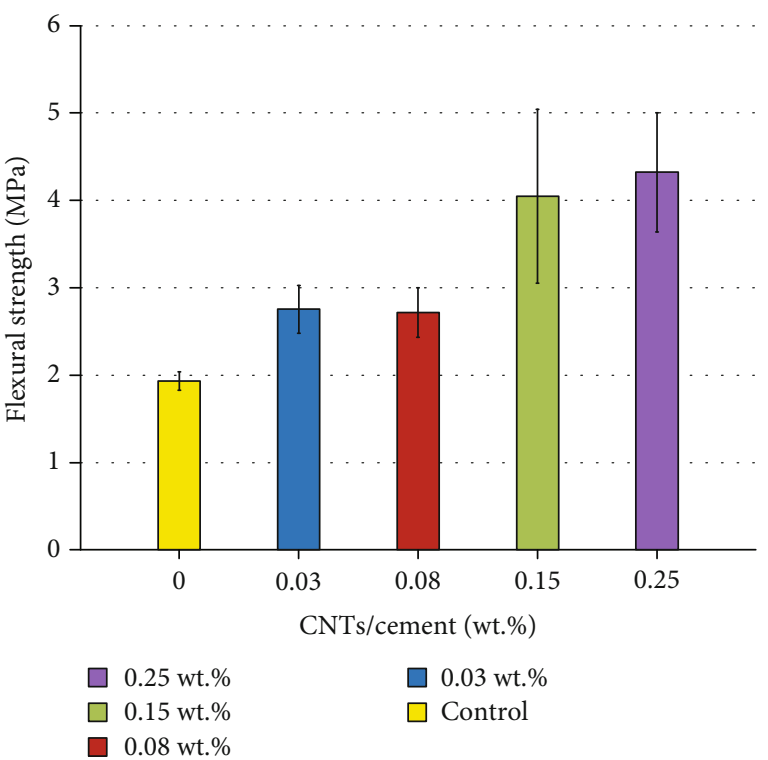

Figure 5: Samples' flexural strength results.

fracture and the nearest support measured on the tension surface of the beam (mm).

(3) If the fracture occurs on the tension surface outside of the middle third of the span length by more than $5 \%$ of the span length, the results of the test were discarded.

The load-deflection curves were determined using an LVDT that was tightly attached to a magnetic holder (Figure 3(a)) and fixed vertically at the sample's bottom midspan (Figure 3(b)). The performed test was a displacement control one with a speed of $2 \mu \mathrm{m} / \mathrm{sec}$.

2.5. Permeability Measurements. The permeability test is a nondestructive method used to evaluate the durability of concrete. The proposed method complies with the European standard, SN, EN 206-1 [35]. The test methodology comprises of determining the air permeability coefficient (kT) as a function of the variation of pressure with time using a permeability tester (Figure 4(a)). First, the test chamber is placed on the concrete surface and the air is then evacuated using the vacuum pump. The rise of the air pressure with time is recorded. Three measurements were done for each tested surface of the concrete sample (Figure 4(b)).

2.6. Microstructural Analysis. Microstructural analysis of the broken samples was performed using a scanning electron microscope (SEM), model Nova NanoSEM. A secondary electron mode of imaging was used to capture the images with two types of scales. The first scale was a large scale between 0.5 and $1 \mathrm{~mm}$ used to examine the void percent, whereas the second scale was a small scale between 1 and 3 micrometers used to investigate the dispersion of the CNTs at the nanolevel. The voltage used was about $5 \mathrm{kV}$, whereas the working distance varied from 4.5 to $8.5 \mathrm{~mm}$. The preparation procedure consisted of first drying the samples using a vacuum chamber, followed by coating them with a goldpalladium to dissipate any excess charges. The thickness of the gold sputtering coating was 10 nanometers every 40 seconds. After that, the samples were mounted rigidly on a specimen holder using a conductive adhesive and the scanning process was then commenced. The microstructure analysis of the SEM images was done using only qualitative techniques to understand the effect of the tested parameters on the strengths obtained for the strongest and weakest specimens. A total of fifteen images were taken for every batch. It was shown, via the analysis, that samples taken from every selected batch were monolithic.

\section{Results and Discussions}

3.1. Flexural Strength Testing. Figure 5 depicts the flexural strength results of CNT concrete batches, including the standard deviation obtained for each batch. The results are the average strengths of six samples prepared for each batch. Low standard deviations in the strength results were observed for the control, 0.03 and $0.08 w t . \%$ CNT batches. On the other hand, high standard deviations were observed for 


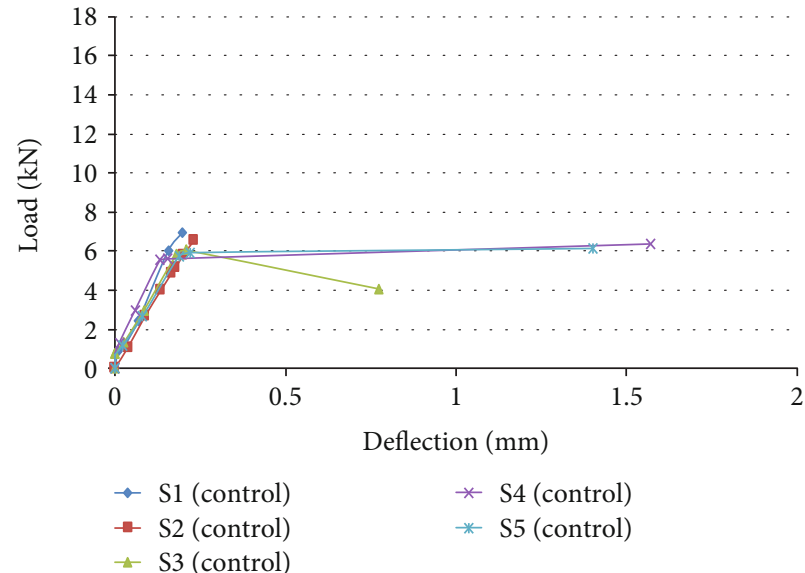

(a)

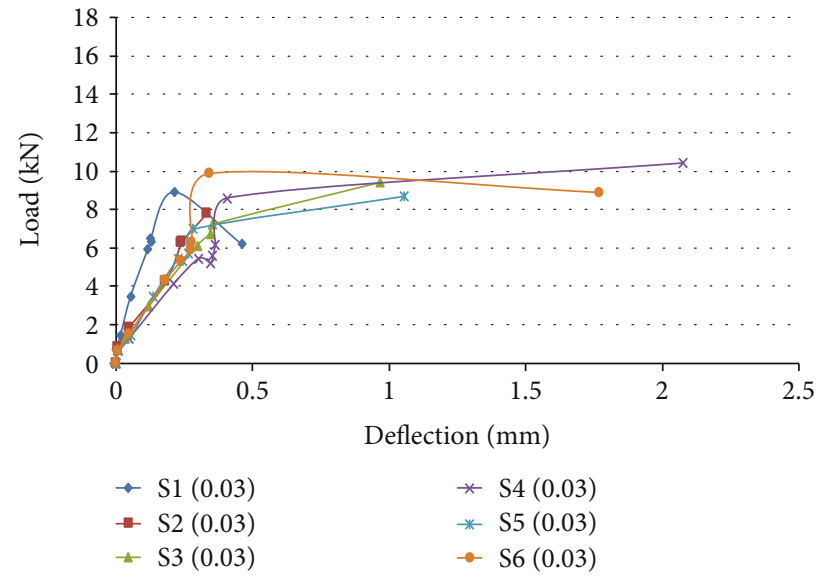

(b)

FIGURE 6: Load-deflection curves for (a) plain concrete (control) samples and (b) 0.03 wt.\% CNT concrete samples.

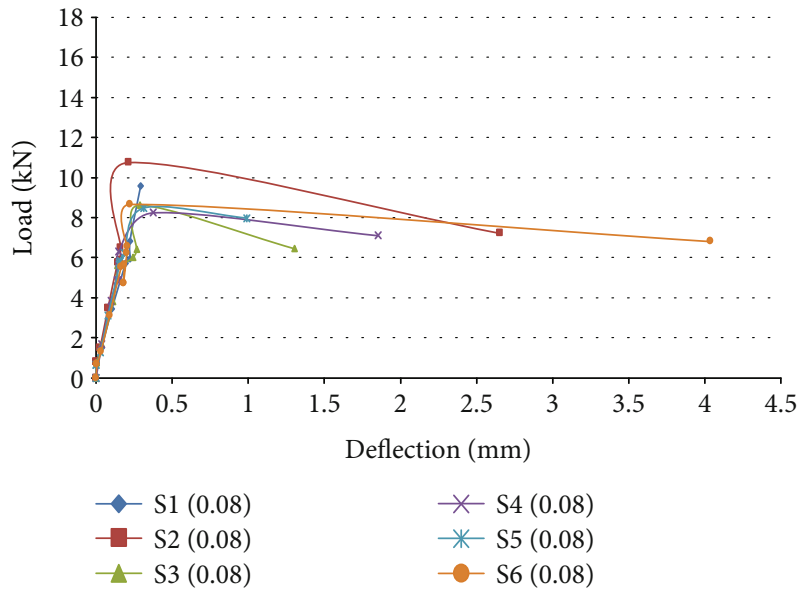

(a)

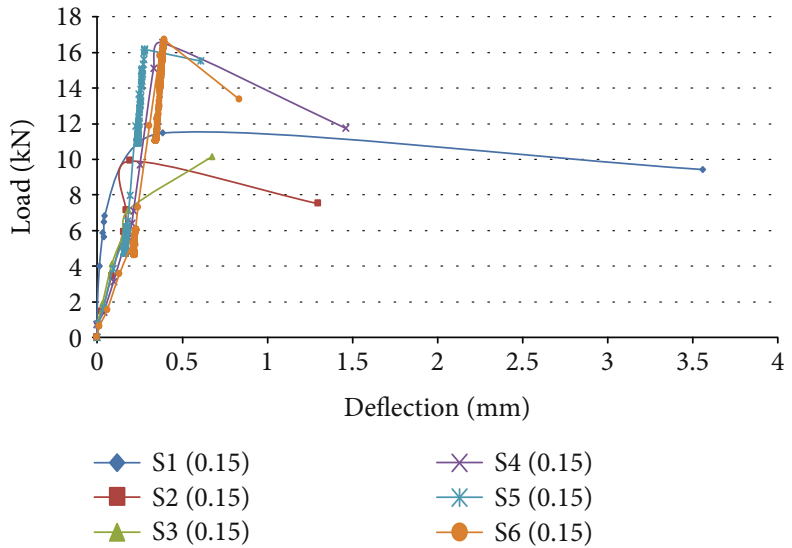

(b)

Figure 7: Load-deflection curves for (a) 0.08 wt.\% CNT concrete samples and (b) 0.15 wt.\% CNT concrete samples.

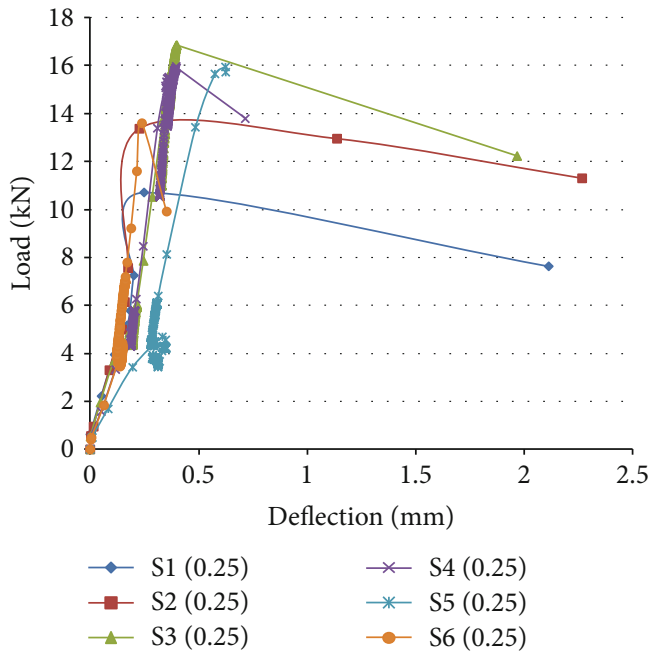

(a)

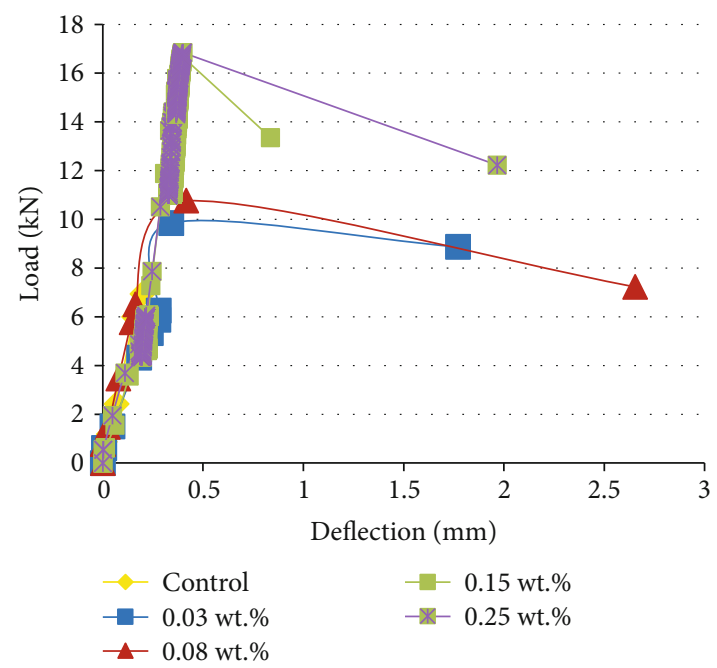

(b)

FIGURE 8: Load-deflection curves for (a) 0.25 wt.\% CNT concrete samples and (b) strongest sample in each batch. 


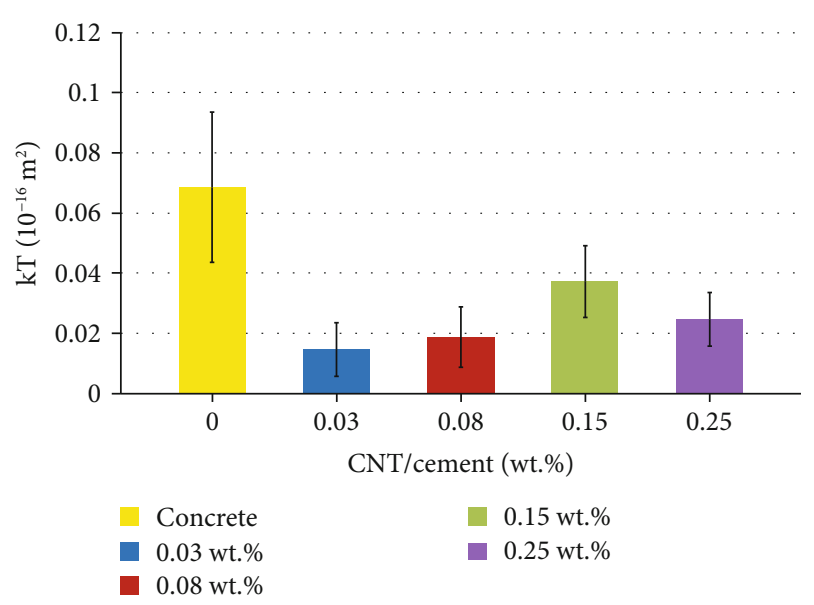

FIgure 9: Permeability test results.

batches with 0.15 and 0.25 wt. $\%$ CNTs. This may be related to the nonuniform dispersion of these batches with the high CNT content. In terms of strength, the results indicated that there was an increase in the flexural strength due to an increase in CNT content. Batches prepared using 0.03 and 0.08 wt.\% CNTs exhibited a strength increase of about $40 \%$ compared with the control concrete batch. With the increase in the nanofilaments' weight fraction, the flexural strength continued to increase. Increments of $109 \%$ and $123 \%$ were obtained in batches prepared using higher CNT contents of 0.15 and $0.25 \mathrm{wt} . \%$, respectively, compared with control concrete.

3.2. Load-Deflection Curves. Figures 6-8 show the loaddeflection curves for all prepared mixes. Each graph shows the results obtained for the six samples prepared for each batch. In general, it was observed that all batches containing CNTs showed more of an erratic load-deflection behavior compared with the plain concrete batch (Figure 6(a)). As discussed in earlier sections, this maybe related to the nonuniform dispersion of CNTs throughout the batch, where a high strain capacity was developed in the locations that contained CNTs and impacted the ability of the composite sample to carry the load and to absorb the energy when it began to fail.

However, to confirm this hypothesis, a microstructural analysis should be performed to investigate CNT dispersion within the concrete constituents. The maximum attained load and deflection for the $0.03 \mathrm{wt} . \%$ CNT batch specimens (Figure 6(b)) were $10.4 \mathrm{kN}$ and $2.074 \mathrm{~mm}$, respectively. These values were higher than the corresponding highest load and deflection measurements of the control concrete batches, which were $6.9 \mathrm{kN}$ and $1.571 \mathrm{~mm}$, respectively. The load behavior of the 0.08 wt.\% CNT batch (Figure 7(a)) was similar to the 0.03 wt.\% CNT batch where larger displacements were recorded after the peak load. The maximum attained load and deflection were $10.7 \mathrm{kN}$ and $4.038 \mathrm{~mm}$, respectively. For batches of high CNT contents of 0.15 and $0.25 \mathrm{wt} \%$ (Figures 7(b) and 8(a)), the load-deflection behaviors were more erratic and showed a high variability in the results obtained for the six samples of the same batch. Again, this may be attributed to the less CNT dispersion within these samples, which resulted in a nonuniform stress distribution in the beams. The maximum attained load and deflection in the 0.15 wt.\% CNT batch specimens were $16.7 \mathrm{kN}$ and $3.558 \mathrm{~mm}$, respectively. On the other hand, the maximum attained load and deflection in the $0.25 \mathrm{wt} . \%$ CNT batch specimens were $16.8 \mathrm{kN}$ and $2.265 \mathrm{~mm}$, respectively. Figure 8(b) shows the results with the highest strength obtained for each batch. For all batches prepared, the sample with $0.25 \mathrm{wt} . \%$ CNTs had the highest loading capacity. Regarding ductility, all CNT-reinforced samples exhibited larger loading and strain capacity compared with plain concrete (more brittle behavior). These findings concur with several earlier studies investigating the effect of CNTs on the ductility of cement paste.

Wang et al. [7] obtained a strain increase of $125 \%$ in deflection at the peak load for a batch of 0.08 wt.\% CNT weight fraction compared with the control cement paste. They also obtained a strain increase of about $50 \%$ in a batch of 0.1 wt.\% CNTs compared with the control cement paste batch. However, for the remaining batches of $0.05,0.12$, and 0.15 wt.\% CNTs, there was a small or no improvement in the ductility results. Similarly, Xu et al. [13] obtained strain increases at the peak load for some CNT cementitious composites compared with control cement paste. However, such strain increases occurred in the batches of the highest CNT contents of 0.1 and $0.2 \mathrm{wt} \%$, as opposed to those batches, prepared using lower CNT contents of 0.025 and 0.05 wt. $\%$. These findings highlight the need to further investigate the optimum CNT weight fraction that would provide the highest flexural strength and strain properties of CNT cementitious composites. Furthermore, there is a need to further investigate the erratic behavior and nonuniform results obtained during load-deflection-based tests.

3.3. Permeability Test. Figure 9 shows the permeability factor results of control concrete and CNT composite batches, including the standard deviation obtained for each batch. The obtained permeability coefficient values are the average values of 18 readings taken for every batch (3 readings multiplied by six samples). A high standard deviation in permeability was observed in control concrete in comparison with the CNT composite batches. In general, the results showed a reduction in the concrete permeability when CNTs were added. The permeability coefficient (kT) decreased 78, 72,45 , and $64 \%$, for the batches prepared using $0.03,0.08$, 0.15 , and $0.25 \mathrm{wt} . \%$, respectively, when compared to the control concrete batch. The results also showed that the decrease in the permeability is not correlated with the CNT weight fraction in the batches. The permeability coefficient decreased for the 0.03 wt.\% CNT batch and then increased up to a CNT weight fraction of $0.15 \mathrm{wt} . \%$. Again, kT decreased in the 0.25 wt.\% CNT batch.

3.4. SEM Microstructural Analysis. Microstructural analysis of the fractured surfaces showed a few observations related to the behavior of the nanofilaments within the concrete hydration products. In terms of dispersion, it was observed that the quality of CNT dispersion in concrete products is 


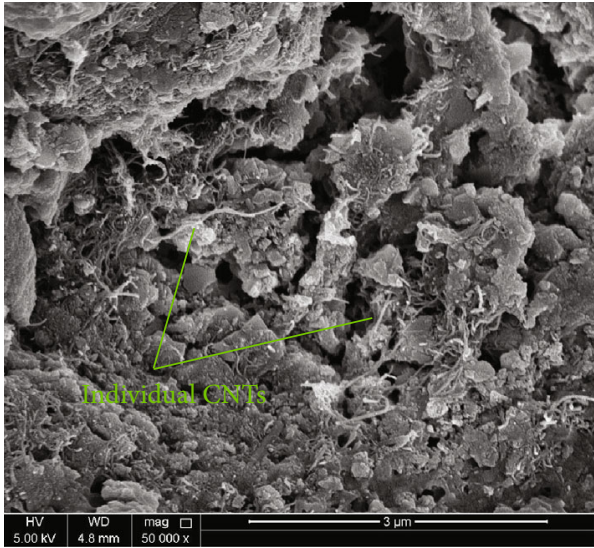

(a)

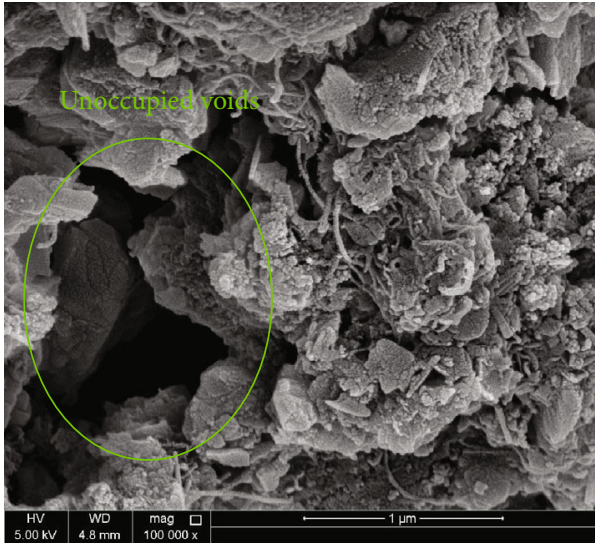

(b)

Figure 10: (a) 0.03\% content batch. (b) Nanoscale voids (scale: 1-3 $\mu \mathrm{m}$ ).

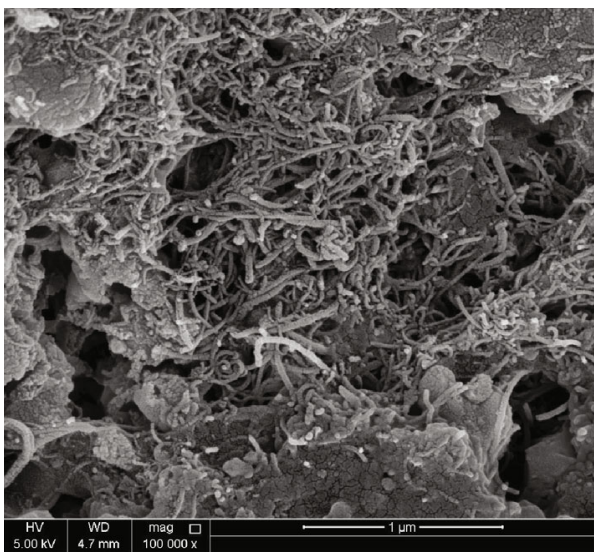

(a)

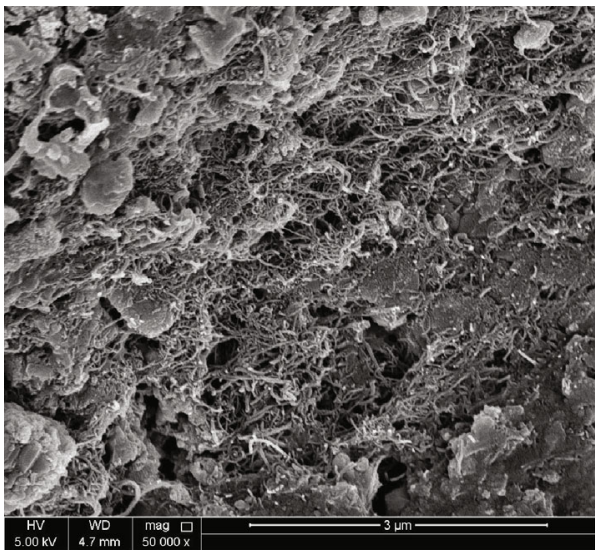

(b)

Figure 11: (a) $0.15 \%$ CNT batch. (b) $0.25 \%$ CNT batch (scale: $1-3 \mu \mathrm{m}$ ).

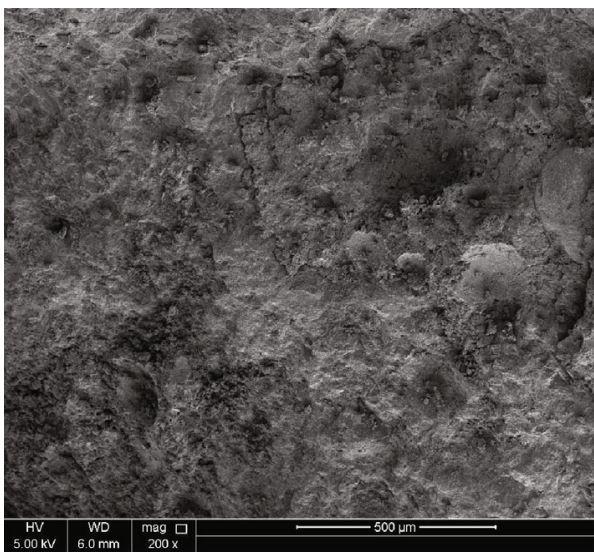

(a)

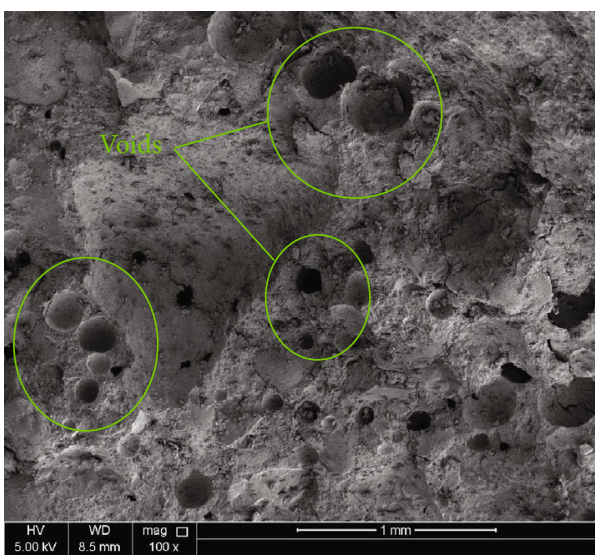

(b)

FIgURE 12: (a) $0.03 \%$ CNT batch. (b) $0.08 \%$ CNT batch (scale: $0.5-1 \mathrm{~mm}$ ).

good in the batches of low CNT content of 0.03 and $0.08 \%$. However, few agglomerations were seen in the batches with higher CNT content of 0.15 and $0.25 \%$. At small scales images of $1-3 \mu \mathrm{m}$, batches of a low CNT content of $0.03 \%$ showed individual fibers at various locations (Figure 10(a)).
However, it was seen that these batches contain a number of empty locations that were not occupied by any filaments (Figure 10(b)). On the other hand, batches of higher CNT contents of 0.15 and $0.25 \%$ were relatively denser and the nanoscale voids were filled with CNTs (Figures 11(a) and 


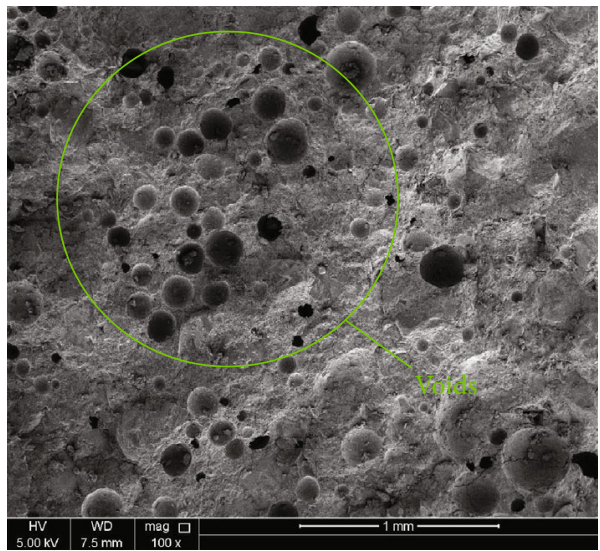

(a)

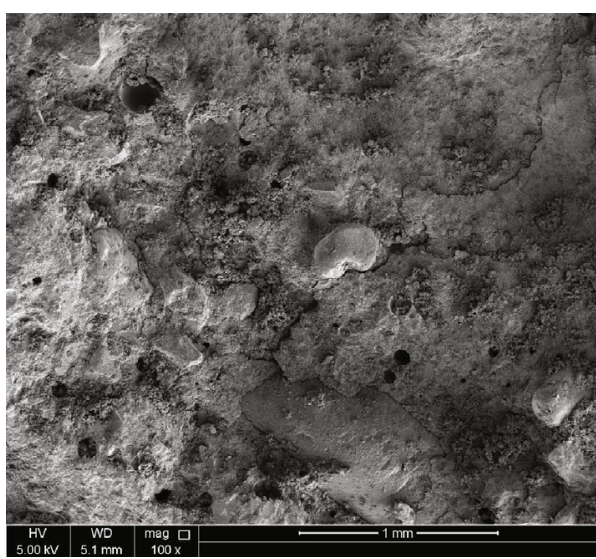

(b)

Figure 13: (a) $0.15 \%$ CNT batch. (b) $0.25 \%$ CNT batch (scale: $0.5-1 \mathrm{~mm}$ ).

11(b)). At large-scale images of 0.5-1 mm (Figures 12 and 13), it was seen that the amount of micron-scale voids is high in the batches of $0.08 \%$ (Figure 12(b)) and $0.15 \%$ (Figure 13(a)) CNT content. This may be related to the effect of the surfactant amount used to disperse the nanofilaments within the solution. Previous research by the authors on the effect of the mixing duration on the properties of cement paste showed that the largest amount of voids occurred in batches containing $0.08 \%$ CNT cement weight fraction [22]. By using qualitative and quantitative microstructural analysis, it was concluded that the larger voids' content is occurring due to the higher surfactant content remaining in the solution after the sonication process.

To correlate strength results with SEM analysis, it was shown that the effect of higher CNT content on the cohesiveness of the samples may be the main reason for the incremental increase in the flexural strength of the samples containing CNTs compared to plain concrete. Higher CNT contents mean denser composites that occupied nanovoids, and hence, this will result in higher flexural strengths and strain capacities. To correlate with permeability measurements, it was not possible to understand the decrease and increase of the CNT samples' permeability via using microstructural analysis. Even though the samples of higher CNT contents of 0.15 and $0.25 \%$ were denser, the permeability values of those samples prepared using lower CNT contents of 0.03 and $0.08 \%$ were lower.

\section{Conclusions}

This study illustrated a few conclusions related to the effect of CNTs' addition on the flexural strength, ductility, and permeability of concrete. The results indicated that high CNT contents of 0.15 and $0.25 \mathrm{wt} . \%$ CNTs would increase the flexural strength of concrete by more than $100 \%$. Furthermore, the results also showed that CNTs would increase the ductility of concrete by about $150 \%$. The permeability test results showed the benefits of CNT addition in reducing the permeability of concrete. The permeability coefficient (kT) decreased by at least $45 \%$ when CNTs were added to concrete. The relationship between concrete's mechanical and physical property improvements and the CNT weight fraction was primarily explained. The addition of CNTs to concrete resulted in a denser composite with higher flexural strengths and strain capacity and lower permeability when compared to plain concrete. The findings of this study could be considered one of the few studies that incorporated CNT addition to concrete to produce composite members of enhanced performance.

\section{Limitations and Future Work}

5.1. Limitations. The limitations observed during this work include the following:

(1) Dispersion of CNTs within the water solution was a time-consuming process due to the need to sonicate limited quantities of a maximum of 1 liter in the repetition

(2) The reduced amount of water in the concrete batches compared to cement paste batches resulted in the nonuniform dispersion of CNTs

\subsection{Future Work}

(1) The elemental compositions of concrete hydration phases must be investigated using energy-dispersive $\mathrm{X}$-ray analysis to understand the effect of CNTs on these phases

(2) There is also a need to further investigate the erratic behavior and nonuniform results obtained during the load-deflection-based tests

\section{Data Availability}

The data used to support the findings of this study are available from the corresponding author upon request.

\section{Disclosure}

The statements made herein are solely the responsibility of the authors. 


\section{Conflicts of Interest}

The authors declare that they have no conflicts of interest.

\section{Acknowledgments}

We express our sincere appreciation and gratitude to the Qatar National Research Fund (QNRF) for funding this research work via NPRP 4-1142-2-440 and PDRA 3-040217003. Furthermore, we acknowledge Qatar National Library's (QNL) support in making this research publishable.

\section{References}

[1] A. G. Abu Taqa, R. K. Abu al-Rub, A. Senouci, N. al-Nuaimi, and K. A. Bani-Hani, "The effect of fiber geometry and interfacial properties on the elastic properties of cementitious nanocomposite material," Journal of Nanomaterials, vol. 2015, Article ID 283579, 14 pages, 2015.

[2] S. Chuah, Z. Pan, J. G. Sanjayan, C. M. Wang, and W. H. Duan, "Nano reinforced cement and concrete composites and new perspective from graphene oxide," Construction and Building Materials, vol. 73, pp. 113-124, 2014.

[3] S. Musso, J. M. Tulliani, G. Ferro, and A. Tagliaferro, "Influence of carbon nanotubes structure on the mechanical behavior of cement composites," Composites Science and Technology, vol. 69, no. 11-12, pp. 1985-1990, 2009.

[4] J. N. de Paula, J. M. Calixto, L. O. Ladeira et al., "Mechanical and rheological behavior of oil-well cement slurries produced with clinker containing carbon nanotubes," Journal of Petroleum Science and Engineering, vol. 122, pp. 274-279, 2014.

[5] R. Siddique and A. Mehta, "Effect of carbon nanotubes on properties of cement mortars," Construction and Building Materials, vol. 50, pp. 116-129, 2014.

[6] A. Sobolkina, V. Mechtcherine, V. Khavrus et al., "Dispersion of carbon nanotubes and its influence on the mechanical properties of the cement matrix," Cement and Concrete Composites, vol. 34, no. 10, pp. 1104-1113, 2012.

[7] B. Wang, Y. Han, and S. Liu, "Effect of highly dispersed carbon nanotubes on the flexural toughness of cement-based composites," Construction and Building Materials, vol. 46, pp. 8-12, 2013.

[8] A. Yazdanbakhsh, Z. Grasley, B. Tyson, and R. Al-Rub, “Carbon nanofibers and nanotubes in cementitious materials: some issues on dispersion and interfacial bond," American Concrete Institute, ACI Special Publication American Concrete Institute, ACI Special Publication, 267, pp. 31-34, 2009.

[9] B. Zou, S. J. Chen, A. H. Korayem, F. Collins, C. M. Wang, and W. H. Duan, "Effect of ultrasonication energy on engineering properties of carbon nanotube reinforced cement pastes," Carbon, vol. 85, pp. 212-220, 2015.

[10] R. K. Abu Al-Rub, A. I. Ashour, and B. M. Tyson, "On the aspect ratio effect of multi-walled carbon nanotube reinforcements on the mechanical properties of cementitious nanocomposites," Construction and Building Materials, vol. 35, pp. 647-655, 2012.

[11] M. S. Konsta-Gdoutos, Z. S. Metaxa, and S. P. Shah, "Multiscale mechanical and fracture characteristics and early-age strain capacity of high performance carbon nanotube/cement nanocomposites," Cement and Concrete Composites, vol. 32, no. 2, pp. $110-115,2010$.
[12] Z. S. Metaxa, J. W. T. Seo, M. S. Konsta-Gdoutos, M. C. Hersam, and S. P. Shah, "Highly concentrated carbon nanotube admixture for nano-fiber reinforced cementitious materials," Cement and Concrete Composites, vol. 34, no. 5, pp. 612-617, 2012.

[13] S. Xu, J. Liu, and Q. Li, "Mechanical properties and microstructure of multi-walled carbon nanotube-reinforced cement paste," Construction and Building Materials, vol. 76, pp. 1623, 2015.

[14] A. Yazdanbakhsh, Z. Grasley, B. Tyson, and R. Abu al-Rub, "Challenges and benefits of utilizing carbon nanofilaments in cementitious materials," Journal of Nanomaterials, vol. 2012, Article ID 371927, 8 pages, 2012.

[15] N. Yazdani and V. Mohanam, "Carbon nano-tube and nanofiber in cement mortar: effect of dosage rate and water-cement ratio," International Journal of Material Sciences, vol. 4, no. 2, 2014.

[16] F. Collins, J. Lambert, and W. H. Duan, "The influences of admixtures on the dispersion, workability, and strength of carbon nanotube-OPC paste mixtures," Cement and Concrete Composites, vol. 34, no. 2, pp. 201-207, 2012.

[17] Y. Hu, D. Luo, P. Li, Q. Li, and G. Sun, "Fracture toughness enhancement of cement paste with multi-walled carbon nanotubes," Construction and Building Materials, vol. 70, pp. 332-338, 2014.

[18] H. K. Kim, I. W. Nam, and H. K. Lee, "Enhanced effect of carbon nanotube on mechanical and electrical properties of cement composites by incorporation of silica fume," Composite Structures, vol. 107, pp. 60-69, 2014.

[19] F. Sanchez and C. Ince, "Microstructure and macroscopic properties of hybrid carbon nanofiber/silica fume cement composites," Composites Science and Technology, vol. 69, no. 7-8, pp. 1310-1318, 2009.

[20] B. M. Tyson, R. K. Abu al-Rub, A. Yazdanbakhsh, and Z. Grasley, "Carbon nanotubes and carbon nanofibers for enhancing the mechanical properties of nanocomposite cementitious materials," Journal of Materials in Civil Engineering, vol. 23, no. 7, pp. 1028-1035, 2011.

[21] A. Yazdanbakhsh, Z. Grasley, B. Tyson, and R. K. A. al-Rub, "Distribution of carbon nanofibers and nanotubes in cementitious composites," Transportation Research Record: Journal of the Transportation Research Board, vol. 2142, no. 1, pp. 8995, 2010.

[22] M. O. Mohsen, N. al-Nuaimi, R. K. Abu al-Rub, A. Senouci, and K. A. Bani-Hani, "Effect of mixing duration on flexural strength of multi walled carbon nanotubes cementitious composites," Construction and Building Materials, vol. 126, pp. 586-598, 2016.

[23] M. O. Mohsen, R. Taha, A. Abu Taqa, and A. Shaat, "Optimum carbon nanotubes' content for improving flexural and compressive strength of cement paste," Construction and Building Materials, vol. 150, no. 2017, pp. 395-403, 2017.

[24] M. O. Mohsen, R. Taha, A. Abu Taqa, N. al-Nuaimi, R. A. al-Rub, and K. A. Bani-Hani, "Effect of nanotube geometry on the strength and dispersion of CNT-cement composites," Journal of Nanomaterials, vol. 2017, Article ID 6927416, 15 pages, 2017.

[25] V. S. Melo, J. M. F. Calixto, L. O. Ladeira, and A. P. Silva, "Macro- and micro-characterization of mortars produced with carbon nanotubes," ACI Materials Journal, vol. 108, no. 3, pp. 327-332, 2011. 
[26] S. Parveen, S. Rana, R. Fangueiro, and M. C. Paiva, "Microstructure and mechanical properties of carbon nanotube reinforced cementitious composites developed using a novel dispersion technique," Cement and Concrete Research, vol. 73, pp. 215-227, 2015.

[27] X. Song, S. Shang, D. Chen, and X. Gu, "Multi-walled carbon nanotube reinforced mortar-aggregate interfacial properties," Construction and Building Materials, vol. 133, pp. 57-64, 2017.

[28] C. Krämer, M. Schauerte, T. Kowald, and R. Trettin, "CNTstabilized foam concrete on the basis of ultra highperformance concrete (UHPC)," 14th International Congress on the Chemistry of Cement, 2015, p. 377, 2015.

[29] C. Krämer, M. Schauerte, T. Müller, S. Gebhard, and R. Trettin, "Application of reinforced three-phase-foams in UHPC foam concrete," Construction and Building Materials, vol. 131, no. 30, pp. 746-757, 2017.

[30] J. Luo, D. Hou, Q. Li, C. Wu, and C. Zhang, “Comprehensive performances of carbon nanotube reinforced foam concrete with tetraethyl orthosilicate impregnation," Construction and Building Materials, vol. 131, no. 30, pp. 512-516, 2017.

[31] X. Wang, I. Rhee, Y. Wang, and Y. Xi, “Compressive strength, chloride permeability, and freeze-thaw resistance of mwnt concretes under different chemical treatments," The Scientific World Journal, vol. 2014, Article ID 572102, 8 pages, 2014.

[32] M. A. Qissab and S. T. Abbas, "Behaviour of reinforced concrete beams with multiwall carbon nanotubes under monotonic loading," European Journal of Environmental and Civil Engineering, vol. 22, no. 9, pp. 1111-1130, 2016.

[33] A. Hawreen, J. A. Bogas, and A. P. S. Dias, "On the mechanical and shrinkage behavior of cement mortars reinforced with carbon nanotubes," Construction and Building Materials, vol. 168, pp. 459-470, 2018.

[34] ASTM C78/C78M - 16, Standard Test Method for Flexural Strength of Concrete (Using Simple Beam with Third-Point Loading), ASTM International, West Conshohocken, PA, USA, 2016.

[35] DIN EN 206, Concrete-Specification, Performance, Production and Conformity (Includes Amendment: 2016), Deutsches Institut fur Normung E.V. (DIN), 2017. 


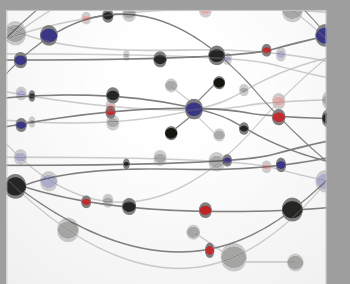

The Scientific World Journal
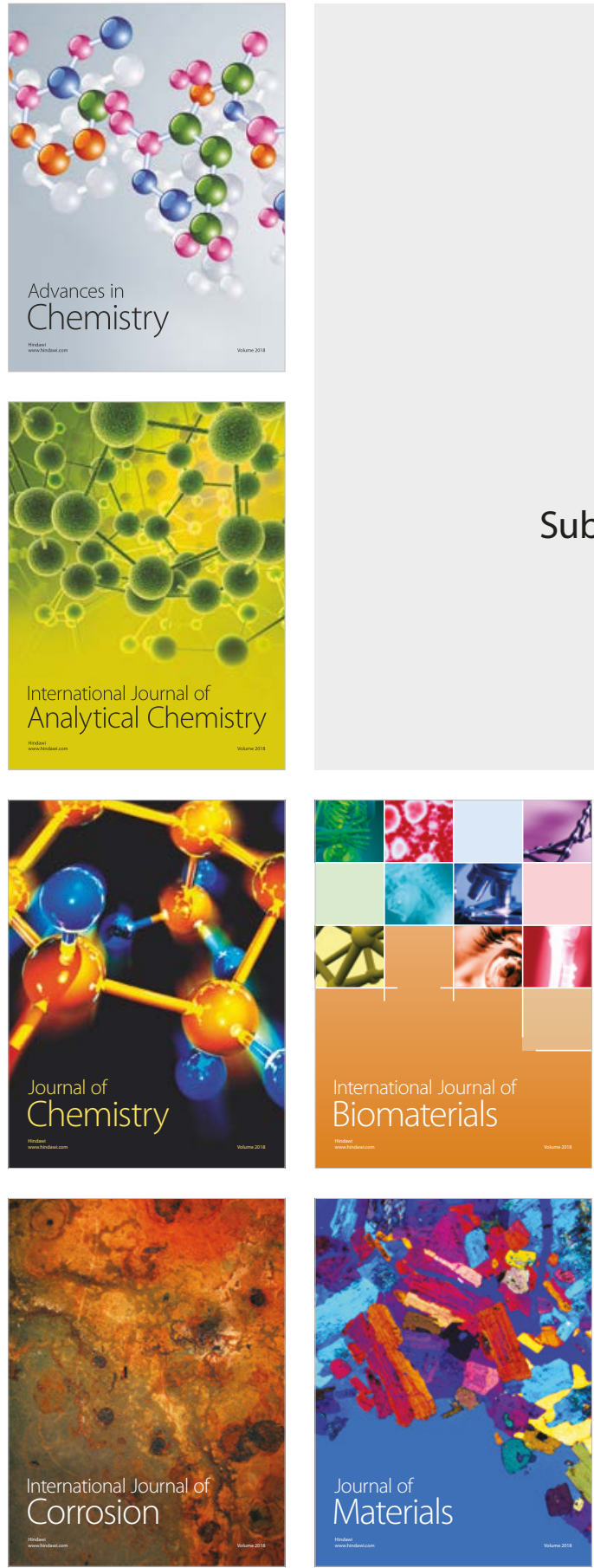

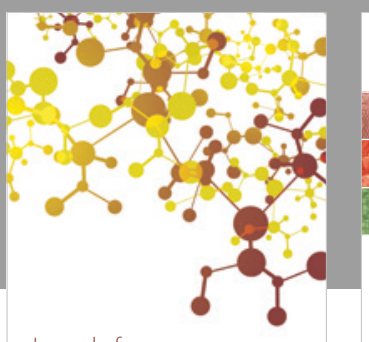

Journal of

Applied Chemistry
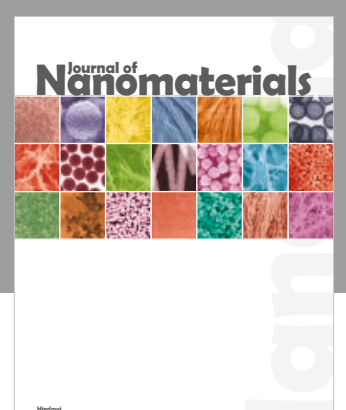

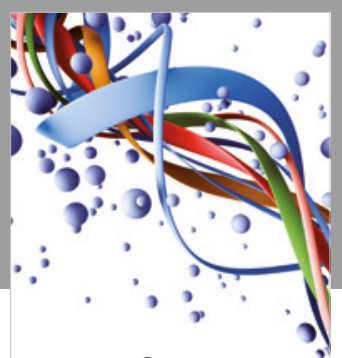

Scientifica

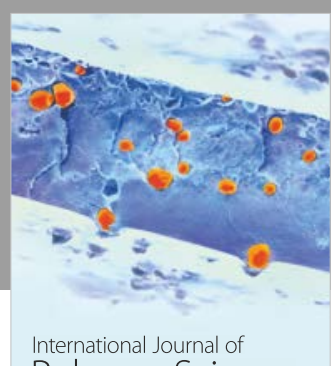

Polymer Science

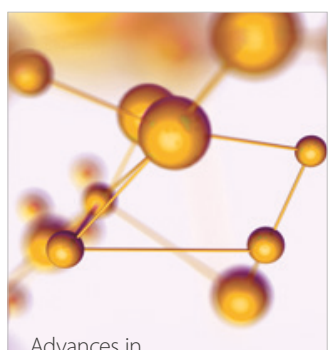

Physical Chemistry
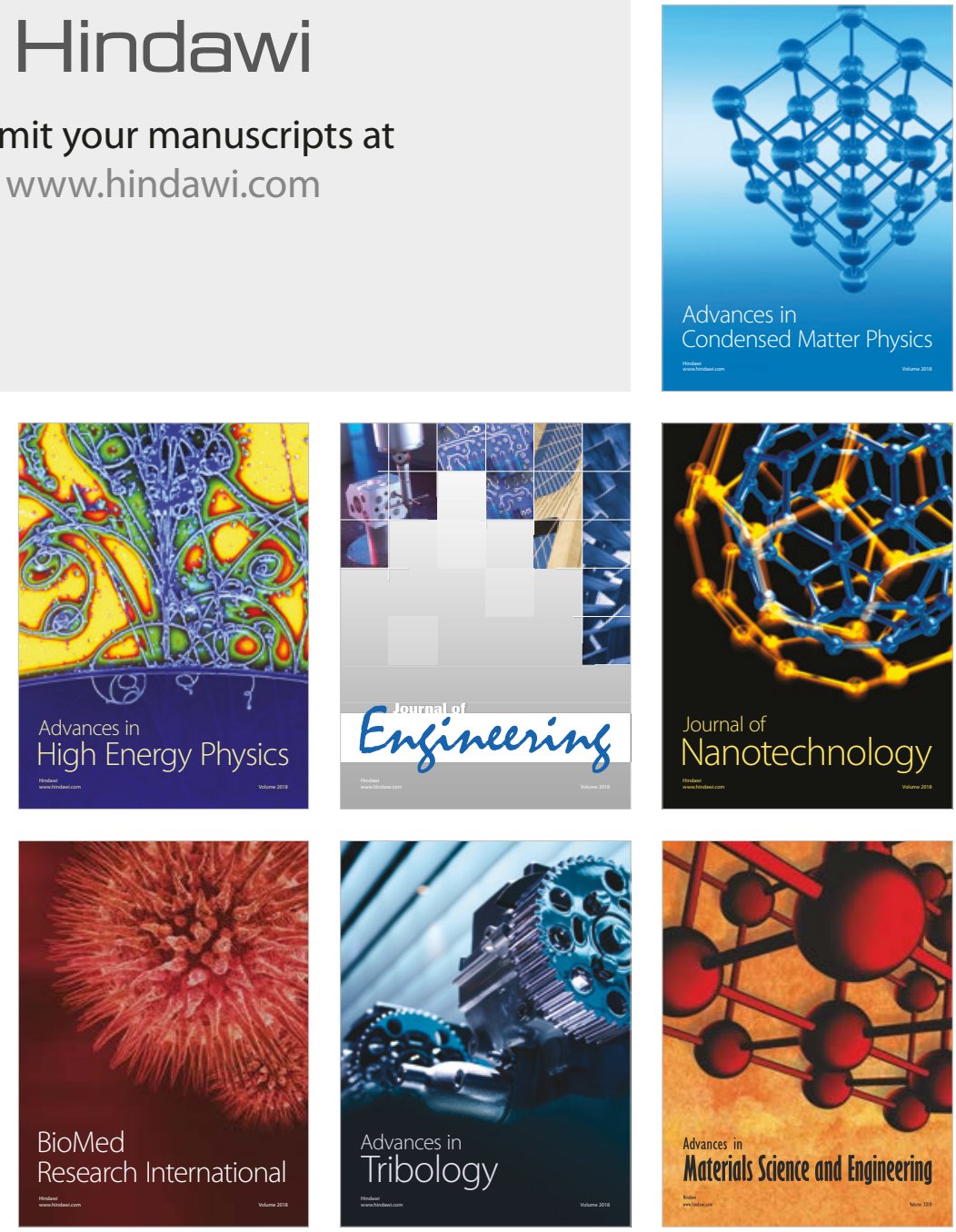